\title{
Correction to: Reality Lost
}

Correction to:

V. F. Hendricks, M. Vestergaard, Reality Lost, https://doi.org/10.1007/978-3-030-00813-0

The book was inadvertently published without the following credit line.

Translated from the Danish by Sara Høyrup / Hoyrup.biz English language copy editing by Vincent F. Hendricks

This has been added to the copyright page of the book.

The updated version of the book can be found at https://doi.org/10.1007/978-3-030-00813-0 